\title{
Bulaşık Makinelerinde Oluşan Plastik ve Gıda Kaynaklı Kokuların Head Space GC-MS İle Tespiti
}

\author{
Canan Ekinci Doğan* \\ * TÜBİTAK MAM Gıda Enstitüsü, Gebze, Kocaeli,Türkiye, (ORCID: 0000-0002-6817-3392), Canan.Dogan@ tubitak.gov.tr
}

(İlk Geliş Tarihi 21 Haziran 2021 ve Kabul Tarihi 22 Ağustos 2021)

(DOI: 10.31590/ejosat.955285)

ATIF/REFERENCE: Ekinci Doğan, C. (2021). Bulaşık Makinelerinde Oluşan Plastik ve Gıda Kaynaklı Kokuların Head Space GCMS İle Tespiti. Avrupa Bilim ve Teknoloji Dergisi, (25), 796-801.

$\ddot{O} \mathbf{z}$

Son yıllarda çelik tabanlı bulaşık makinelerinin göreceli olarak daha maliyetli olması sebebiyle üreticiler, çelik yerine kullanılacak plastik malzemeler üzerine yoğun araştırmalar yapmaktadır. Yapılan araştırmalar sonucunda maliyeti düşük, katkılı polietilen ve polipropilen gibi malzemeler çelikten yapılmış tabanların yerine geçmeye başlamıştır. Ancak petrol ürünü olan plastik malzemelerin doğal olarak içerdiği moleküller bulaşık makinelerinin içerisine istenmeyen koku yayarak tüketici tercihini azaltmaktadır. Bu çalışmanın amacı bulaşık makinelerinin tabanlarında kullanılmak üzere üretilmiş plastik tabanlarda yıkama esnasında oluşan plastik ve gıda kaynaklı kötü kokuların tespit edilmesidir. Çalışmada kalsiyum içeren polipropilen plastik tabanlı (Caplastik) ve talk içeren plastik tabanlı (Talkplastik) bulaşık makineleri, karşılaştırma yapılabilmesi için de çelik taban(Çelik) bulaşık makinesi kullanılmışıtr. Çalışma sonuçlarında düşük sıcaklıklarda Caplastik tabandan 2,2,3,3-tetrametil bütan ve 2-pentadekanol bileşikleri açığa çıkmıştır. talk-plastik malzemeden ise yüksek sıcaklıklarda dimetildiazon,4-metil oktan, 4,7-dimetilundekan ve 5,8-dietildodekan bileşiklerinin yayıldığı tespit edilmiştir. Gıdalarla kirletildikten sonra yapılan yapılan çalışmalarda da plastik kaynaklı olarak tetrametilbütan, 2pentadekanol, dimetildiazon, 4-metil oktan, 4,7-dimetilundekan, 5,8-dietildodekan ve dioksalan bileşikleri tespit edilmiştir. Ancak çelik tabanlı bulaşı makinesinde diğer ikisinden farklı olarak gıda kaynaklı moleküller tespit edilebilmiştir.

Anahtar Kelimeler: Plastik Taban, Polipropilen, GC-MS, Gıda, Kötü Koku, Bulaşık Makinesi.

\section{Plastic and Food Based Taints and Off-Odours Detection in Dishwashers}

\begin{abstract}
In recent years, due to the relatively more costly cost of steel-based dishwashers, manufacturers have been conducting intensive research on plastic materials instead of steel. As a result of the research studies, low-cost and additive polyethylene and polypropylene materials have begun to replace steel bases. However, the molecules naturally contained in plastic materials, which are petroleum products, reduce the consumer preference by emitting an undesirable odour inside the dishwashers. The aim of this study is to determine the plastic and food-borne off taints or unwanted odors that occur during washing on plastic based produced for use on the base of dishwashers. In the study, calcium-containing polypropylene plastic-based (Caplastic) and talc-containing plastic-based (Talcplastic) dishwashers, and steel-based (Steel) dishwashers were used for comparison. In the results of the study, In the results of the study, 2,2,3,3-tetramethyl butane and 2-pentadecanol compounds were released from the Caplastic base at low temperatures. Dimethyldiazon, 4-methyl octane, 4,7-dimethylundecane and 5,8-diethyldodecane compounds were detected to diffuse from the talcplastic material at high temperatures. In studies carried out after contamination with food, tetramethylbutane, 2-pentadecanol, dimethyldiazon, 4-methyl octane, 4,7-dimethylundecane, 5,8-diethyldodecane and dioxalan compounds were detected as plastic origin. However, unlike the other two, food-borne molecules could be detected in the steel-based dishwasher.
\end{abstract}

Keywords: Plastic, Polypropylene, GC-MS, Food, Taints and Off-Flavours, Dishing Washer.

*Sorumlu Yazar: Canan.Dogan@tubitak.gov.tr 


\section{Giriş}

Polipropilen plastikler, termoplastikler sinıfinda yer alan poliolefinlerin bir türü olan, düşük fiyat ve geniş uygulama alanları ile en çok tercih edilen polimerik malzemelerdendir. $\mathrm{Bu}$ malzeme ağırlıklı olarak otomotiv sektörü, gıda ambalajları, lamineli filmler ve optik uygulamalar olmak üzere pek çok sektörde doğrudan veya çeşitli katkı maddeleri ile fonksiyonel hale getirildikten sonra yaygın olarak kullanılmaktadır. Türkiye plastik sektörü raporuna göre (PAGEV, 2017), ülkemizde 2018 y1l içinde PETKİM tarafindan 137 bin ton polipropilen plastik malzeme üretildiği ve aynı yıl ithal ettiğimiz polipropilen miktarının da yaklaşı 2.243 bin ton civarında olduğu raporlanmıştır. Poliolefinler karbon ve hidrojen atomlarından oluşur ve aromatik yapıda olmazlar. Genellikle ektrüzyon, enjeksiyon kalıplama (injection moulding), blow ve rotational kalıplama metotları ile işlenmektedir. Bütün poliolefinlerin doğal özelliği onların polar ve gözeneksiz, özel yükseltgenme ön işlemleri yapılmadan boya ve lakları kabul etmeyen düşük enerjili yüzeye sahip olmasıdır. Polipropilenler üç ana temel polimerik oluşuma sahiptir: isotaktik, sindiyotaktik ve ataktik. Şekil 1'de polipropilenin polimerik formları gösterilmiştir.

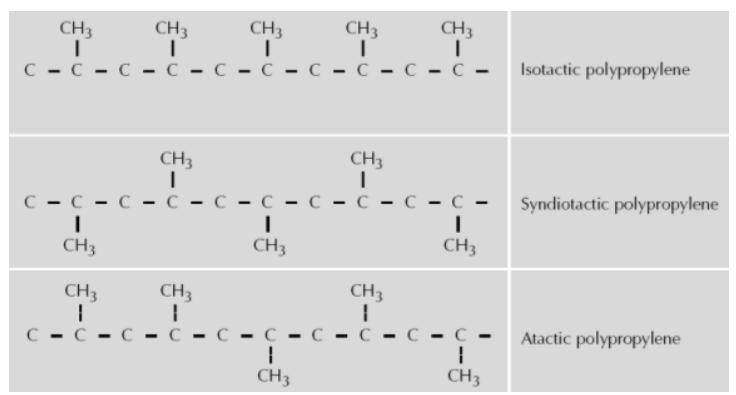

Şekil 1. Polipropilenin polimerik formları

Plastiklerin işlenebilmesi ve fiziksel özelliklerinin iyileştirilebilmesi için organik ve inorganik katkı maddeleri polimerlere ve yardımcı plastiklere katılmaktadır (Avrupa Plastik üreticileri birliği, 2008; Anderson vd.,2004; Tolinski, 2015). Bu yeni katkılı plastikler yüksek sicaklıklara maruz kaldığında içeriğinde bulunan kimyasalların bozunması sebebiyle koku molekülleri açığa çıkmaktadır. Ancak, kokuya sebep olan bu moleküllerin veya plastiklere ilave edilen katkı maddelerinin, plastiklerin temas ettiği gıda gibi yaşamsal ürünlerin organoleptik özelliklerini değiştirmemesi ve yapılarını bozmaması yasal olarak gereklidir (TGK, 2019/44; EU, 1935/2004).

Plastiklere ilave edilen katkı maddeleri içerisinde en çok kullanılan kaydırıcı ajanlar oleamid ve erukamid gibi yağ asidi amidleridir (Molnar, 1974, Bart, 2006, Murphy 2001, Brody vd, 2008.). Birkaç mikron partikül boyutuna sahip killer de (talk gibi) parçacık yapıcı dolgu maddeleri olarak kullanılmaktadır. Ayrıca $\mathrm{TiO}_{2}$ ve $\mathrm{CaCO}_{3}$ gibi inorganik bileşikler de beyaz plastik üretmek için polimerlere katılabilmektedir. Dolgu maddesi olarak $\mathrm{CaCO}_{3}$ gibi bazı inorganiklerin plastiklere katılması, plastiklerin dayanım etkisi ve termal dayanıklılık gibi özelliklerini geliştirmekte ancak sertlik ve gerilim dayanıklılığını azaltmaktadır (Nwabunma ve Kyu 2008). Ayrica polimerik matriksler ile bir araya getirilen inorganik katkılar bitmiş üründe rengin koyulaşmasına sebep olmakta ve polimer yapısında küçük molekül ağırlıklı bileşikler oluşabildiği için istenmeyen kokulara da sebep olmaktadır. Bunun yanında, katkılı plastiklerin degredasyonu sebebiyle göreceli yüksek sıcaklıklarda farklı e-ISSN: 2148-2683 bozunma ürünleri oluşmakta bu oluşan ürünlerde istenmeyen plastik bazlı kokulara sebebiyet vermektedir (Austin, 1990, Mottarm, 1998, Sajilata vd. 2007, Baigrie, 2003). Oluşan koku, kapalı ortamda yandığı zaman hayvansal veya bitkisel bozunma ürünlerine benzeyen tuhaf koku/tat veya "empyreuma kokusu" olarak tanımlanmaktadır (Villberg ve Veijanen 2001).

Plastik malzemeler içerisindeki kötü/istenmeyen koku bileşiklerinin varlığı koku veya aromadaki değişimlerden anlaşılabilir. Birçok molekül kokuya sebep olabilir ancak düşük konsantrasyondaki kokuları insan duyuları algılamayabilir. Bu sebeple, enstrümantal cihazlar ile kötü veya istenmeyen kokuların tespiti yoğun çalışmaların sürdürüldüğü araştırma konulardan biridir (Canellas ve ark., 2010; Hopfer vd..2010,Mottarm, 1998, Eiceman vd., 2002, Vilberg vd., 1997). Genellikle koku analizleri iki şekilde yapılmaktadır:

1.) Kokuya sebep olan ve bilinen bileşikler uygun cihazlar ile tespit edilir.

2.) Kokuya sebep olan ve bilinmeyen bileşiklerin tespitinin yapılabilmesi için enstrümantal cihazlar ile farklı yöntemlerin kullanılması gerekebilir.

Çeşitli ortamlarda doğal olarak bulunan veya oluşan kötü kokulu bileşiklerin analizlerinde çeşitli analitik teknikler kullanılmaktadır. İlk zamanlarda kullanılan tekniklerin başında çözücülerin kokuları içerisine hapsetme performansına dayanan sıv1-sıv1 ekstraksiyon, buhar destilasyonu veya buhar destilasyonu ile çözücü ekstraksiyonunun birleştirildiği ekstraksiyon teknikleri gelmiştir (Kolb vd., 2006). Daha sonraki çalışmalarda kapalı ortamda yapılan sabit ve hareketli headspace sistemleri öne çıkmıştır. $\mathrm{Bu}$ yöntemleri takip eden ve koku analizlerinde kullanılan metotlardan biri katı faz üzerinde mikroekstraksiyondur (SPME) (Dutra vd., 2011, Ezquerro vd. 2002, Espert vd.,2005, Hodgson vd., 1998). En son geliştirilen metot da GC-MS'e olfaktometrinin bağlantılı hale getirildiği ve yine SPME fiberlerinin kullanıldığı ve elektronik burun ile stir bar sorptive extraksiyon teknikleridir (Kolb vd., 2006, Ridgway vd., 2010.).

Son yıllarda tüketicilerin daha bilinçli olması ve plastik üretimlerindeki artan mevzuatların uygulanma gereksiniminden dolayı plastik üreticileri ürünlerinde yer alan bileşiklerinin ne olduğunu bilmeye ihtiyaç duymaktadırlar. Özellikle istenmeyen koku içeren plastik malzemeler tercih edilmemektedir. Plastik kaynaklı kötü kokulu bileşikleri içeren plastik malzemelerin kullanıldığg ürünlerde tüketici tercihini azalttığı da bilinmektedir. Bunun yanında, poliolefinlerdeki kötü kokulu bileşikler özellikle gida ile temas eden ortamlarda malzeme kalitesinde risk oluşturmaktadır.

$\mathrm{Bu}$ çalışmada maliyet sebebiyle tercih edilen iki farklı bileşimden oluşan Ca-plastik ve Talk-plastik tabanlı bulaşık makinesi ile çelik tabanlı bulaşık makinesi yıkama protokolleri yapıldıktan sonra içeride kalan plastik ve gıda kaynaklı kötü kokular karşılaştırılmıştır. Karşılaştırmalar klasik çelik taban bulaşık makinesine göre yapılmıştır.

\section{Materyal ve Metot}

\subsection{Kullanılan Kimyasal Maddeler ve Cihazlar}

Plastik malzemelerin tanımlanmasında Perkin Elmer marka ATR-FT-IR kullanılmıştır. Malzemelerdeki koku analizlerinde Perkin Elmer marka GC-MS Turbo Matrix 40 Trap Headspace örnekleyici, Perkin Elmer marka Clarus Gaz Kromatografisi ve detektör olarak da Clarus 600 T Kütle Spektrofotometrisi 
kullanılmıştır. Kolon olarak Elite 5-MS (Metilpolisiloksan (5\% fenil)- $30 \mathrm{~m}$; 0.250 I.D., $0.25 \mu \mathrm{m}$ ) ve Wax (PEG-60 m, 0.250 I.D., $0.25 \mu \mathrm{m}$ ) kolonları kullanılmıştır. GC-MS ve Headspace şartları Tablo 1'de yer almaktadır. Organik çözücüler GC saflıkta kullanılmıştır. Kullanılan SPME fiber $100 \mu \mathrm{m}$ polidimetilsiloksan kaplama ve $65 \mu \mathrm{m}$ divinil benzen yapısındadır. Plastik ve çelik tabanlı bulaşık makinesi Arçelik, talk katkılı plastik taban Bosch markadır.

\subsection{Malzeme Analizleri}

Deneysel çalışmada ve bulaşık makinelerinin $\left(\mathrm{CaCO}_{3}\right.$ katkılı polipropilen - Caplastik ve talk katkılı polipropilen - talkplastik) tabanında kullanılan malzemeler piyasadan temin edilmiştir. $\mathrm{Bu}$ çalışmada beş farklı polipropilen malzeme karşılaştırılma amacıyla kullanılmıştır. $\mathrm{Bu}$ malzemeler $\mathrm{CaCO}_{3}$ katkılı polipropilen malzeme (CaPlastik), talk katkılı polipropilen malzeme (TalkPlastik), homopolimer malzeme, kopolimer malzeme, kokusuz polipropilendir. Tablo 2'de headspace (HS) koşulları verilmiştir.

\subsection{Plastik Malzemelerde Koku Analizleri}

Bütün malzemelerin koku analizleri için gaz kromatografisi tekniği kullanılmıştır. Çalışmalar 2 gruba ayrılmıştır. 1.Grup çalışmalarda: Polipropilen malzemeler farklı sıcaklık ve sürelerde head space viallerinde bekletilerek (Tablo 2) malzemelere ait GC toplam iyon kromatogramları elde edilmiştir. 2.Grup çalışmalarda: 50 ve $70{ }^{\circ} \mathrm{C}^{\prime}$ lerde bulaşık makineleri çalıştırılarak adsorpsiyon testleri yapılmıştır. $\mathrm{Bu}$ çalışmaya göre, İki farklı yıkama programı koşulunda (ekonomi $50{ }^{\circ} \mathrm{C}$ ve Yoğun $70{ }^{\circ} \mathrm{C}$ programı) her 3 bulaşık makinesinde (CaPlastik, TalkPlastik ve Çelik Taban) temiz yıkama ve kirli yıkama yapılmıştır. Çalışmalarda koku analizlerinin yapılabilmesi için SPME fiber kullanılmıştır. SPME fiber 1 saat bulaşık makinesinin içinde bekletilerek koku molekülleri tutulmuş ve akabinde GC'ye enjekte edilmek suretiyle desorpsiyon işlemi yapılmıştır. Çalışma sonucunda koku moleküllerine ait toplam iyon kromotogramları elde edilmiştir. İki farklı sıcaklıkta yapılan program altta anlatılmıştır:

Temiz Yıkama çalışmasında amaç, seçilen bulaşık makinelerinde temiz yıkama yapılması ve içeride temiz yükün bekletilmesi durumunda koku oluşumunun ve onun tespitinin yapilmasidir.

Çalışmanın birinci haftasında, bütün bulaşık makinelerinin başlangıç durumlarına ait örnekleri SPME ile alınmıştır. Bu örneklerin ardından bulaşık makinelerinde temiz yükler ile yıkamalar yapılmış, program sonunda ve 24 saat sonunda SPME ile örnekleri alınmış ve GC kromatogramları elde edilmiştir. Makinelerde ikinci kez temiz yükler ile yıkama yapılmış yine program sonunda ve 48 saat sonunda SPME ile örneklerin alınmıştır. Makineler 1 hafta daha bekletilmiş ve SPME ile örnekler alınmıştır.

Kirli Yıkama çalışmasında amaç bulaşık makinelerinde kirli yüklerin bekletilmesi ve ardından yıkama yapılması durumunda koku oluşumunun tespitinin yapılmasıdır. Burada bulaşık makineleri kirli yükler ile yüklenmiş, makineler 3 gün boyunca bekletilmiş ve 12 saat aralıklarda SPME ile örnek alınmıştır. Makinelerde yıkama yapılmıştır. Program sonunda ve 24 saat sonunda SPME ile örnekler alınarak kromatogramlar elde edilmiştir.
Tablo 1. GC-MS ve Headspace koşulları

\begin{tabular}{|c|c|}
\hline Headspace & TurboMatrix 40 Trap \\
\hline İğne $\mathrm{T}$ & $90^{\circ} \mathrm{C}$ \\
\hline Transfer line $\mathrm{T}$ & $100{ }^{\circ} \mathrm{C}$ \\
\hline Firın T & $80^{\circ} \mathrm{C}$ \\
\hline Trap'in en düşük T & $40^{\circ} \mathrm{C}$ \\
\hline Trap'in en yüksek T & $280^{\circ} \mathrm{C}$ \\
\hline Trap'te tutma süresi & 6 dak. \\
\hline Isıtma süresi & 60 dak. \\
\hline Basınçlandırma süresi & 1 dak. \\
\hline $\begin{array}{l}\text { Basıncı kaldırma } \\
\text { süresi }\end{array}$ & 2 dak. \\
\hline Kolon basincı & $25 \mathrm{psi}$ \\
\hline Vial basıncı & $10 \mathrm{psi}$ \\
\hline Transfer line & Fused silika1mx $320 \mu \mathrm{m}$ \\
\hline GC & Clarus 600 \\
\hline Enjektör T & $200^{\circ} \mathrm{C}$ \\
\hline Sicaklık Programı & $\begin{array}{l}\text { Firın T:35 }{ }^{\circ} \mathrm{C}(\mathbf{5} \mathbf{d}) ; 3{ }^{\circ} \mathrm{C} \\
/ d ; 160^{\circ} \mathrm{C}(15 \mathbf{d})\end{array}$ \\
\hline Taşıyıcı Gaz & Helyum \\
\hline $\begin{array}{l}\text { Taşıyıcı Gaz Akış } \\
\text { Hızı }\end{array}$ & $1.0 \mathrm{~mL} / \mathrm{dak}$ \\
\hline Split oranı & splitless \\
\hline MS & Clarus $600 \mathrm{~T}$ \\
\hline $\begin{array}{l}\text { MS İyonizasyon } \\
\text { Voltaj1 }\end{array}$ & $70 \mathrm{eV}$ \\
\hline MS İyon Kaynak T & $200^{\circ} \mathrm{C}$ \\
\hline MS tarama aralığ 1 & 33-350 a.m.u. \\
\hline $\begin{array}{l}\text { Elektron çoğaltıcı } \\
\text { voltajı }\end{array}$ & $350 \mathrm{~V}$ \\
\hline Tarama zamanı & 0.25 saniye \\
\hline $\begin{array}{l}\text { Tarama arası bekleme } \\
\text { zamanı }\end{array}$ & 0,05 saniye \\
\hline
\end{tabular}

Tablo 2. HS koşulu (sıcaklık ve bekletme süresi parametresi)

\begin{tabular}{|c|c|c|}
\hline Numune & $\begin{array}{c}\text { Sicaklık } \\
\left({ }^{\circ} \mathrm{C}\right)\end{array}$ & $\begin{array}{c}\text { Bekletme } \\
\text { süresi } \\
\text { (saat) }\end{array}$ \\
\hline Tüm numuneler & 40 & 1,5 \\
Tüm numuneler & 45 & 1,5 \\
Tüm numuneler & 50 & 1,5 \\
Tüm numuneler & 60 & 1 \\
Tüm numuneler & 68 & 1 \\
\hline
\end{tabular}




\section{Araştırma Sonuçları ve Tartışma}

\subsection{Polipropilen malzemelerin tanımlanması ve Head Space GC-MS ile incelenmesi}

CaPlastik ve TalkPlastik malzemelerinin ATR-FT-IR ile spektrumları alınarak ve cihaz kütüphanesinde karşılaştırma yapılması suretiyle tanımlamaları yapılmıştır. Şekil 2'de polipropilen malzemelere ilişkin spektrum yer almaktadır. Sonuçta numuneler izotaktik polipropilen olarak tanımlanmıştır.

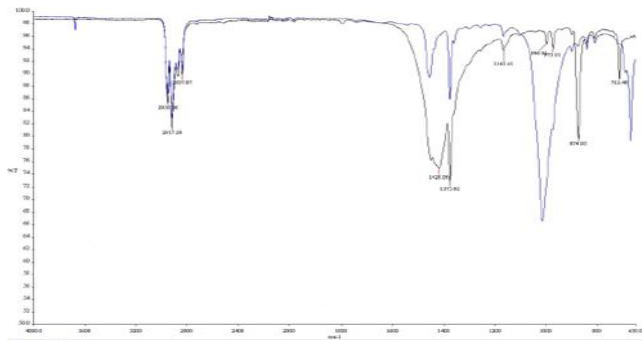

Şekil 2. Polipropilen malzemelerin ATR-FT-IR spektrumu (Siyah çizgi: CaPlastik taban; Mavi çizgi: TalkPlastik taban)

\subsection{Polipropilen malzemelerden yayılan koku bileşiklerinin GC-MS ile analizleri}

Çalışma kapsamında CaPlastik taban, TalkPlastik taban, homopolipropilen, kopolipropilen ve kokusuz polipropilen malzemeler ile birlikte HS GC-MS'de farklı sicaklık ve sürelerde (Çizelge 2.) bekletilmiştir. Çalışmalarda iki farklı kolon kullanılmış ancak 60 metrelik wax kolon koku çalışmalarında daha iyi sonuçlar vermiştir. Sonuçlarda head space ünitesinde sıcaklık arttıkça kokudan sorumlu moleküllerin hem sayıca hem de \% olarak artış gösterdiği görülmüştür. Polipropilen numunelerinin $68{ }^{\circ} \mathrm{C}$ 'de 1 saat bekletme yapıldıktan sonra GC kromatogramları elde edilmiştir ve sonuçlar Şekil 3.'de verilmiştir.

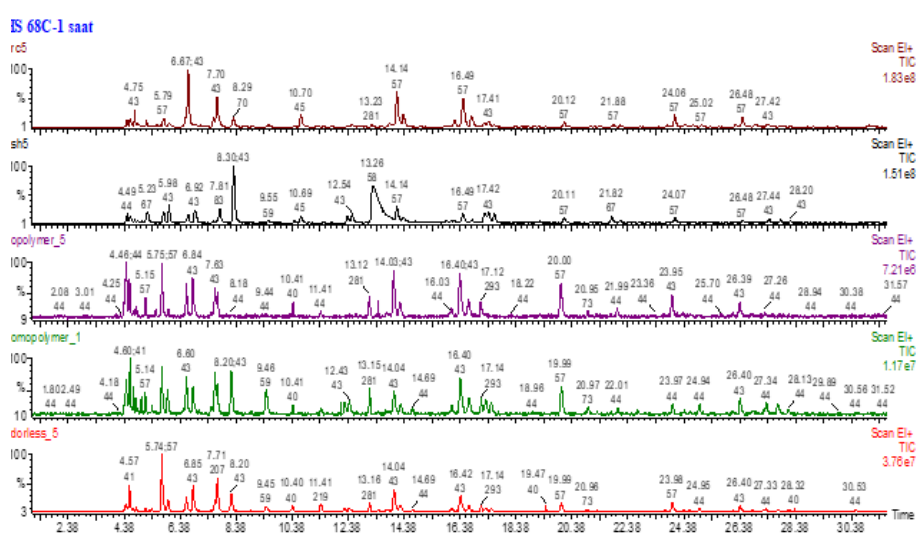

Şekil 3. $68^{\circ} \mathrm{C}$ 'de 1 saat GC-MS HS ünitesinde bekletme sonucu elde edilen GC-MS toplam iyon kromatogramı (ARC 5: CaPlastik taban, BSH5: Talkplastik taban, kopolimer 5: kopolimer polipropilen, homopolimer1: homopolimer polipropilen, odorless 5: kokusuz polipropilen)

$\mathrm{Bu}$ çalışmalar sonucunda koku molekülleri belirlenmiş ve literatüre göre tanımlanmıştır (Anderson vd., 2004; Hopfer vd., 2010; Canellas vd.,2010). Plastik malzemelerden adsorbanlara tutunan koku moleküllerinin; 2-metil-pentan, 2,2,3,3 tetrametil butan, 4-metil-oktan, etil alkol, 4,7-dimethyl undekan, 5,7dimetil undekan, 2,3,6,7- tetrametil oktan bileşikleri olduğu görülmüştür. Bu bileşikler uçucu ve kokulu bileşikler olarak literatür ile de eşleştirilmiştir (Ezquerro vd.,2002; Austin, 1990; Mottarm, 1998).

\subsection{Ekonomi 50 ve Yoğun 70 Programı ile Temiz Koşullarda Açığa Çıkan Koku Analizleri}

İki farklı yıkama programı koşulunda (ekonomi 50 ve yoğun 70) her üç bulaşık makinesinde (Caplastik taban, Çelik taban ve talk plastik taban) temiz yıkama yapılmıştır. Burada birinci hafta her üç bulaşık makinesinin başlangıç durumlarına göre örnekler alınmıştır. İlk hafta, Makineler temiz yükler ile yıkanmış, ilk yıkama (1.yıkama) ve 24 saat sonra (2.yıkama) olmak üzere 2 kez ölçüm alınmıştır. Ardından makineler tekrar temiz yükler ile yıkanmış, ilk yıkama (3.yıkama) ve 48 saat sonra (4.yıkama) olmak üzere $2 \mathrm{kez}$ daha ölçüm alınmıştır. İkinci hafta makineler bekletilmiş ve ikinci haftanın sonunda tekrar örnek (5. Ölçüm) alınmıştır.

Çalışmalarda kokuya sebep olan moleküllerin analizlerinin yapılabilmesi için SPME fiber kullanılmıştır. SPME fiber 1 saat bulaşık makinesinin içinde bekletilerek içeride bulunan koku molekülleri fibere adsorplanmış ve GC'ye enjekte edilmek suretiyle desorpsiyon işlemi yapılmıştır. Koku moleküllerine ait GC toplam iyon kromotogramları elde edilmiştir.

Şekil 4.'deki toplam iyon kromatogramına göre 1 hafta bekletildikten sonra, bulaşık makinelerinin temiz koşulda (ekonomi 50 programında) ölçülen bileşikler dodekan, dioksalan, hekzilheptadekan ve oktadekadiyonik asit metil esterdir.

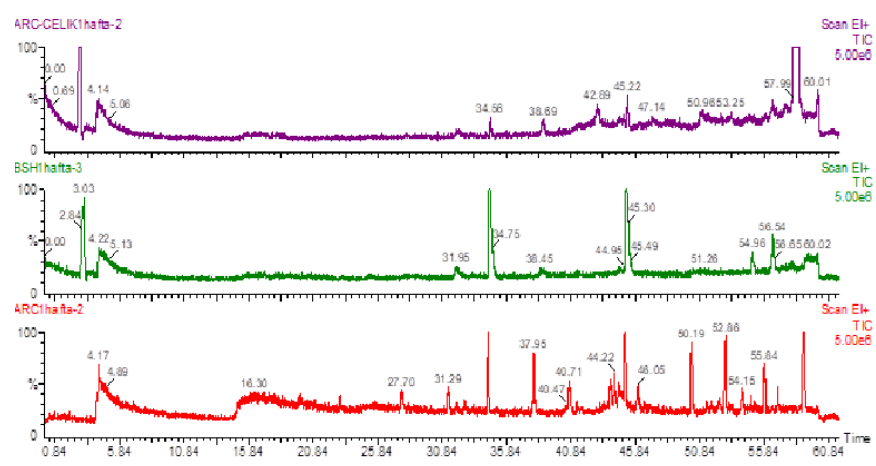

Şekil 4. Ekonomi 50 programında bulaşık makineleri 1 hafta bekletildikten sonra elde edilen temiz yıkama sonuçlarına ilişkin GC-MS Kromatogramı (üst Çelik taban, orta Talk-Plastik taban ve alt Ca-Plastik Taban).

Şekil 5.'deki kromatograma göre de 1 hafta bekledikten sonra bulaşık makinelerinin temiz koşulda (yoğun 70 programında) bulunan bileşikler oluşan/azalan pikler dioksolan, Heptanal, Hekzilheptadekan, Okzaik asit, Disikloetanol, Oksiren-2-bütil-3-metil, Oktadekadiyonik asit metil ester, 4morfolinetanamin'dir.

\subsection{Ekonomi 50 ve Yoğun 70 programı ile Kirli koşullarda açığa çıkan Koku Molekülleri}

İki farklı yıkama programı koşulunda (ekonomi 50 ve yoğun 70) her üç bulaşık makinesinde (Caplastik taban, Çelik taban ve talk plastik taban) temiz yıkama yapılmıştır. 


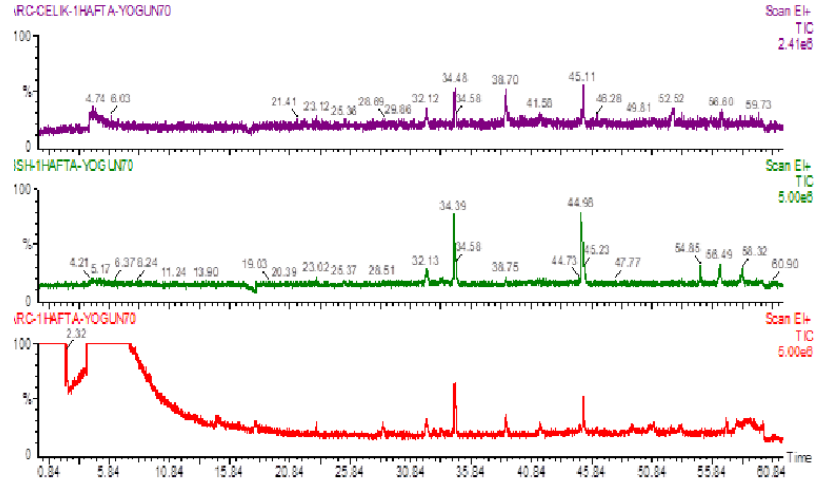

Şekil 5. Yoğun 70 programında bulaşık makineleri 1 hafta bekletildikten sonra elde edilen temiz yıkama sonuçlarına ilişkin GC-MS Kromatogramı (üst Çelik taban, orta Talk-Plastik taban ve alt Ca-Plastik Taban)

Çalışma ekonomi 50 ve yoğun 70 olarak 2 farklı yıkama koşulunda yapılmıştır. Birinci hafta her üç bulaşık makinesinde başlangıç durumlarına göre ölçümler alınmıştır. Ardından kirli yükler ile 3 gün boyunca 12 saat ara ile ve kirli yüklerin yıkamas1 yapıldıktan 24 saat, 48 saat ve 96 saat sonunda SPME fiber ile örnekler alınmıştır. Ardından makineler tekrar temiz yükler ile yıkanmış ve programın sonunda yine SPME fiber ile örnekler alınmıştır. Bu işlemlerin sonunda yeniden 48 saat sonra SPME fiber ile örnekler alınmıştır. SPME fiber'den desorpsiyon yapıldığında elde edilen toplam iyon kromatogramları Şekil 6. ve Şekil 7.'de gösterilmiştir.

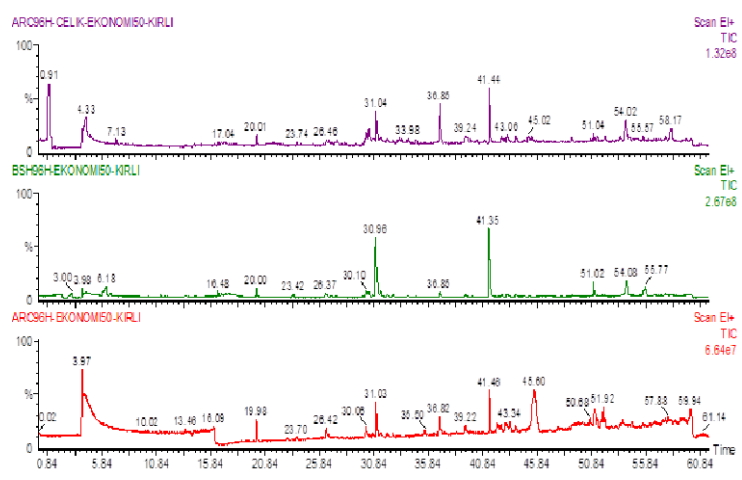

Şekil 6. Ekonomi 50 programında bulaşık makineleri 96 saat bekletildikten sonra elde edilen kirli yıkama sonuçlarına ilişkin GC-MS Kromatogramı (üst Çelik taban, orta Talk-Plastik taban ve alt Ca-Plastik Taban)

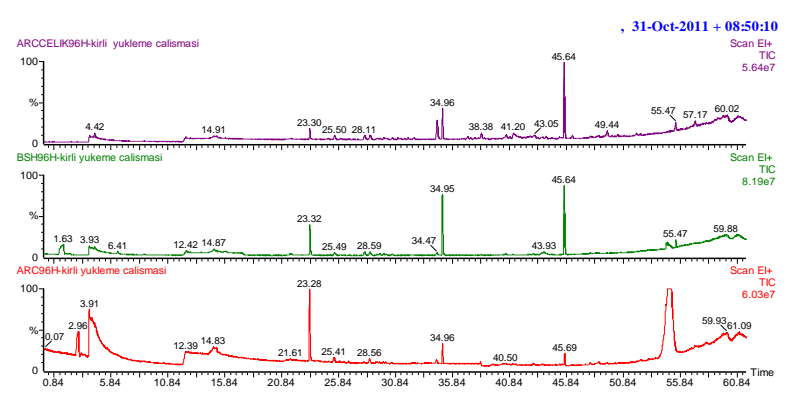

Şekil 7. Yoğun 70 programında bulaşık makineleri 96 saat bekletildikten sonra elde edilen kirli yıkama sonuçlarına ilişkin GC-MS Kromatogramı (üst Çelik taban, orta Talk-Plastik taban ve alt Ca-Plastik Taban)
Bulaşık Makinelerine yüklenen kirler margarin, kıyma, 1spanak, çay, süt ve yulaf olarak seçilmiştir. Kirli bekletme koşulunda oluşan dietilen glikol monometil eter bileşikleri peynir/süt ürünlerinden kaynaklanabilmektedir. Oktadekanoik asit (stearik asit) kaynağı elma, kayısı ve avokado gibi meyveler olabilmektedir. Butanamit yine peynir kaynaklı, dioksalan bileşiklerinin sebebi de kahve kreması, Paraguay çayı, tavuk eti ve bira(arpa) kaynaklı olmaktadır. Sebze kirlerinde heptanal, dekanal bileşikleri açığa çıkmaktadır. Yine etilamin bileşiği de et ve bira ile ilgilidir. Ayrıca yedi karbonlu metil ketonlar da peynir kaynaklı oluşmaktadır.

Başlangıçta talk-plastik tabanlı makinede, kirli koşulda oluşan bileşiklere bakıldığı zaman trimetildekan, butanetriol, glisin, tetradekan, diaminodipropilamin, trimetildodekan, tetradekan bileşiklerinin oluştuğu görülmüştür. Ca-plastik tabanlı makinede trimetildekan ve glisin hariç diğer bileşikler yer alırken, çelik tabanlı makinede daha az sayıda kokudan sorumlu pik yer almıştır. 96 saat sonunda Ca-plastik tabanlı makinede trimetildekan, tetrametildekan, trimetildodekan bileşikleri artış göstermiştir. Talk-plastik tabanlı makinede ise trimetildodekan, trimetil dekan, tetradekan bileşiklerinde artış oluşmuştur.

Talk-plastik ve Ca-Plastik tabanlı bulaşık makinelerinde plastik kaynaklı moleküller olarak tetrametilbütan, 2pentadekanol, dimetildiazon, 4-metil oktan, 4,7-dimetilundekan, 5,8-dietildodekan ve dioksolan bileşiği kromatogramlarda yer almaktadır. Dioksolan hariç her üç molekül literatürde termal oksidasyon proseslerinden gelen ana koku maddesi olarak değerlendirilmektedir.

Temiz yıkama koşullarında 1 hafta sonunda oluşan/artış gösteren moleküllerin ağırlıklı olarak plastik kaynaklı olduğu görülmüştür. Ancak kirli koşulda yıkama sonrası elde edilen toplam iyon kromatogramlardaki diaminodipropilamine ve glisin bileşiğinin de protein kaynaklı gıdalardan kaynaklandığı görüşmüştür. Talk-plastik ve Ca-Plastik tabanlı bulaşık makinelerinde ekonomi 50 ve yoğun 70 programda 96 saat sonunda elde edilen kromatogramda yer almayan ancak çelik tabanlı bulaşık makinesinin kromatogramında yer alan bileşikler ise sadece gıda kaynaklıdır. Bu bileşikler değerlendirildiği zaman: metoksi asetik asit, tridesilester, trifloroasetoksipentadekan, tetradekan, diaminodipropilamin ve butantriol olduğu görülmüştür.

\section{Sonuç}

Çalışma sonucunda Ca-plastik taban, talk-plastik taban, homopolipropilen, kopolipropilen ve kokusuz polipropilen malzemeler tek başına Head space GC-MS'de farklı sıcaklık ve bekletme koşulları altında bekletilmiştir. Caplastik tabanın polipropilen malzemesinde diğer polipropilen malzemelerden farklı olarak düşük sicaklıklarda 2,2,3,3-tetrametilbütan ve 2pentadekanol, yüksek sicaklıklarda ise dimetildiazon, 4-metil oktan ve 4,7-dimetilundekan bileşikleri belirlenmiştir. Ca-plastik tabanlı bulaşık makinesinde başlangıç anındaki muhtemel koku molekülü 5,8-dietildodekan ve dioksalan bileşiği, talk-plastik tabanlı bulaşık makinesinde ise dioksolan türevi moleküller olarak belirlenmiştir.

Bulaşık makineleri ekonomi 50 ve yoğun 70 programı ile çalıştırılmıştır. Temiz ve kirli yıkama koşulları altında bulaşık makinelerindeki koku molekülleri makinelerin içerisinde SPME fiberi bekletilerek GC-MS'de analiz edilmiştir. Temiz koşulda Caplastik taban ve talkplastik plastik tabanda yer alan ancak çeliktabanda yer almayan moleküller dodekan ve dioksalan 
moleküllerine ait piklerdir. Bulaşık makinelerinin kirli olması durumundaki 24 saat bekletilme sonunda oluşan pikler talkplastik tabanda 2,4-dimetil heptan, 6-metil oktan ve undekan'dır. Ca-plastik tabanda ise 5-etil,2-metil oktan,2hekzadekanol ve dekan bileşiğidir. 1 hafta bekletilmesi sonucunda talkplastik tabanlı bulaşık makinesinde oluşan moleküller glisin, oktadekan, dodekan, floroasetoksipentadekan ve hekzadekanol bileşiğidir. 1 hafta bekletilme sonucunda Caplastik tabanda oluşan herhangi bir pik tespit edilememiştir.

Hayatımızın her noktasında ucuz ve kolay bulunurluğu sebebiyle vazgeçilmez olan petrol kökenli plastik malzemeler özellikle gıda ile temas alanlarında yaygın olarak kullanılırken diğer taraftan da sağlık endişeleriyle tüketicileri bilinçli olmaya zorlamaktadır. Gıda ve su gibi hayati ihtiyaçlarımızla temas durumundaki plastiklerin içerikleri ve sağlığa etkileri yapılan multidisipliner çalışmalar ile literatürde kendisine yer bulurken güncelliğini de korumaktadır. Bu çalışma kapsamında plastik malzemelerin üretiminde kullanılan kimyasal bileşiklerin artan sıcaklıkla parçalandığı ve ortaya çıkan yeni göreceli küçük kimyasalların gıda dışı kötü kokuların kaynağı olabileceği görülmüş̧tür.

\section{Teșekkür}

Yazar laboratuvar çalışmaları sırasında verdiği destekten dolayı Bülent Karadeniz ve Vedat Yalçınkaya’ya teşekkür eder.

\section{Kaynakça}

Andersson, T., Holmgren, M.H., Nielsen, Y. \& Wessle B.(2005). Degradation of Low Density Polyethylene During Extrusion. IV. Off-Flavor Compounds in Extruded Films of Stabilized LDPE, Journal of Applied Polymer Science, 95, 583-595.

Austin, R.G.(1990). Degredation Studies of Polyolefins, $1^{\text {st }}$ edition CRC Press.

Baigrie, B. (2003) Taints and off-flavours in food, ed:., CRC press, Cambridge England

Bart, C.J. (2006). Plastics Additives Advanced industrial Analysis. IOS press Amsterdam Netherlands.

Brody, A., Bugusu, B., Han, J.H., Sand, C.K. \& Mchugh, T.H. (2008). Innovative Food Packaging Solutions, Journal of Food Science, 73(8), 13-18.

Burdock G.A. (2009). Fenaroli's Handbook of Flavor Ingredients, Fourth edition, CRC press, Boca Raton.

Canellas, E., Aznar, M., Nerin, C. \& Merceab P. (2010). Partition and diffusion of volatile compounds from acrylic adhesives used for food packaging multilayers manufacturing, J. Mater. Chem., 20, 5100-5109.

Dutra, C., Pezo, D., Alvarenga, F. M., Nerin, C. \& Reyes, F. (2011). Determination of volatile organic compounds in recycled polyethylene terephthalate and high-density polyethylene by headspace solid phase microextraction gas chromatography mass spectrometry to evaluate the efficiency of recycling processes. Journal of Chromatography A, 1218 1319-1330.

Eiceman, G.A., Bergloff, J.F., \& Funk P.A. (2002). Comparison of Emission Profiles for Volatile Organic Compounds from Cotton and Polypropylene-based Tarp. The Journal of Cotton Science 6:40-51.

Espert, A., Heras, L. \& Karlsson S. (2005). Emission of possible odourous low molecular weight compounds in recycled biofibre/polypropylene composites monitored by head-space SPME-GC-MS. Polymer Degradation and Stability 90, 555562.

Ezquerro, O., Pons, B. \& Tena M.T. (2002). Development of a headspace solid phase microextraction-gas chromatographye mass spectrometry method for the identification of odorcausing volatile compounds in packaging materials. J.Chromatogr A 963(1-2):381-92.

EU Food Contact Material Framework Regulation (EC) No 1935/2004 (Framework regulation)

Hodgson, S.C., O’Connor, M.J., Casey, R.J. \& Biggers S.W. (1998). Toward an optimized dynamic headspace method for the study of volatiles in low-density polyethylene. J Agric Food Chem. 46(4):1397-405.

Hopfer, H., Haar, N., \& Leitner, E. (2010). Analytical method for identification of odour-active compounds in polyolefins. In Expression of Multidisciplinary Flavour Science (pp. 561-564). Zurich University.

Kolb, B. \& Ettre, L.S. (2006) Static Headspace-gas chromatography Theory and Practice, Wiley Interscience $2^{\text {nd }}$ edition by john Wiley and Sonsi INC., Hoboken, New Jersey.

Molnar, N. M. (1974). Erucamide"Journal of the American Oil Chemists Society. 51 (3), 84.

Mottarm, D.S. (1998). Chemical tainting of foods, International Journal of Food Science and Technology, 33, 19-29.

Nwabunma, D. \& Kyu, T. (2008) Polyolefin composites 2008 John Wiley and Sons, Inc., Hoboken,

Murpy, J. (2001). Additives for Plastic Handbook" $2^{\text {nd }}$ Ed. Elsevier Science Ltd., New Jersey.

PAGEV (2017)- Türkiye plastik sektör raporu..

Plastics Europe Association of plastics manufacturer (2008).

Ridgway, K., Lalljie, S.\& Smith R.M. (2010). An alternative method for analysis of food taints using stir bar sorptive extraction, Analytica Chimica Acta, 677 29-36.

Sajilata ,M.G., Savitha, K., Singhal, R.S., Kanetkar, V.R. (2007) Scalping of Flavors in Packaged Foods, Comprehensive Reviews in Food Science and Food Safety, Vol. 6, 17-35.

Tolinski, M. (2015). Additives for Polyolefins: Getting the Most out of Polypropylene, Polyethylene and TPO, 2. Ed. Published by Elsevier)

TGK, Türk Gıda Kodeksi Gıda ile Temas Eden Madde ve Malzemeler Tebliğ (Tebliğ No: 2019/44)

Villberg, K., Veijanen, A., Gustafsson, I. \& Wickstrom, K. (1997). Analysis of odor and taste problems in high-density polyethene. J Chromatogr A, 791(1 -2):213-9.

Villberg, K. \& Veijanen, A. (2001) Analysis of a GC/MS thermal desorption system with simultaneous sniffing for determination of off-odor compounds and VOCs in fumes formed during extrusion coating of low-density polyethylene. Anal Chem. 73(5):971-7. 